\title{
A REESTRUTURAÇÃO DA REDE URBANA DO OESTE BAIANO E SUA ORGANIZAÇÃO SOCIOESPACIAL NO INÍCIO DO SÉCULO XXI
}

\author{
The urban net restructure of Bahia's west region and its social and spatial organization \\ during the beginning of 21ST century
}

Iann Dellano da Silva Santos*

*Doutorando em Geografia pela UFG - iann.dellano@hotmail.com.

\author{
Recebido em 15/05/2018. Aceito para publicação em 25/06/2018. \\ Versão online publicada em 10/08/2018 (http://seer.ufrgs.br/paraonde)
}

\begin{abstract}
Resumo: Este artigo tem como objetivo compreender a atual organização socioespacial da rede urbana do Oeste Baiano, destacando a posição geográfica favorável de Barreiras e a célere ascensão de Luís Eduardo Magalhães, no sentido de entender os papéis urbanos desses respectivos centros no início do século XXI. Na recombinação de elementos da rede urbana do Oeste Baiano, resultantes de processos sociais, políticos e econômicos imbricados com a inserção da agricultura moderna na região de cerrado, ocorridos nas últimas décadas, e que implicaram em uma urbanização quantitativa e qualitativa nos centros tradicionais e nos novos aglomerados, é possível alcançar, de uma maneira inteligível, o padrão espacial do conjunto de centros funcionalmente articulados desse tipo particular de rede.
\end{abstract}

Palavras-chave: Rede urbana. Organização socioespacial. Papéis urbanos.

\begin{abstract}
This paper has as mais goal to comprehend the current social and spatial organization of Bahia's west region's urban network, highlighting favorable Barreiras' geographic position and the rising of Luís Eduardo Magalhães city, to understand the urban roles of this amount of centers, in the beginning of 21st Century. Recombining elements of the urban network of West Baiano, resulting from social, political and economic processes involved in the insertion of modern agriculture in the cerrado region, occurred in the last decades, which implied a quantitative and qualitative urbanization in the traditional centers and in the new agglomerations, it's possible to achieve, intelligibly, the spatial pattern of the set of functionally articulated centers of this particular type of network.
\end{abstract}

Key-words: Urban Network. Spatial and social organization. Urban roles.

\section{Introdução}

A rede urbana compõe-se de um conjunto de centros que, por sua vez, desempenham "[...] papéis diretamente associados a dois amplos circuitos de exploração dos centros de acumulação de capital e poder sobre a região" (BESSA, 2010, p. 37). Tais circuitos efetuam-se, como sugere Corrêa (1989, p. 75), por meio de "[...] um multivariado processo de criação, apropriação e circulação dos valores excedentes", estando inseridos na divisão territorial do trabalho que, por sua vez, impõe distinção entre os centros urbanos, entre os segmentos de rede urbana, entre as regiões, enfim, entre os espaços, pois a divisão territorial do trabalho "cria uma hierarquia entre lugares e redefine, a cada momento, a capacidade de agir das pessoas, das firmas e das instituições" (SANTOS; SILVEIRA, 2013, p. 21). 
O padrão simples de rede urbana, estruturado desde o século XIX em forma dendrítica (SANTOS FILHO, 1989), sofre um processo de reestruturação entre as décadas de 1970 e 1980, sobretudo a se destacar duas características: i) a mudança da posição geográfica favorável para o centro de Barreiras na década de 1970, conectado por malha rodoviária a dois grandes centros urbanos, Salvador e Brasília, retirando Barra do eixo central da rede (DINIZ, 1982), e reestabelecendo novas articulações dentro e fora da região, culminando ao próprio crescimento urbano de Barreiras e uma crescente articulação regional, ou seja, uma maior centralidade; e ii) as recentes criações urbanas oriundas da agricultura moderna entre as décadas de 1970 e 1980, em especial Luís Eduardo Magalhães.

Basicamente, esses dois elementos demonstraram o rompimento com o padrão simples de rede urbana, configurando uma rede de localidades centrais de média complexidade, que se instaura como base para a plena inserção do modo produção capitalista na região. Nesse sentido, torna-se imprescindível investigar as novas relações de produção a partir do final do século XX e início do século XXI, levando em conta a recombinação dos elementos constituintes da rede urbana, no intuito de tornar o atual padrão de rede inteligível.

Este artigo tem como objetivo compreender a atual organização socioespacial da rede urbana do Oeste Baiano, destacando a posição geográfica favorável de Barreiras e a célere ascensão de Luís Eduardo Magalhães, ainda no final do século XX, no sentido de entender os papéis urbanos desses respectivos centros.

Nesse sentido, este artigo verifica os elementos constituintes da rede urbana, sobretudo os papéis urbanos desempenhados por Barreiras e, recentemente, por Luís Eduardo Magalhães. Segundo Bessa (2015, p. 174), "a combinação particular desses elementos, num dado espaço-tempo, determina a composição espacial de uma rede urbana". Na recombinação dos principais elementos da rede urbana do Oeste Baiano, resultantes de processos sociais, políticos e econômicos imbricados com a inserção da agricultura moderna na região de cerrado, ocorridos no final do século XX e início do século XXI, e que implicaram em uma urbanização quantitativa e qualitativa nos centros tradicionais e nos novos aglomerados, é possível alcançar, de uma maneira inteligível, o padrão espacial do conjunto de centros funcionalmente articulados desse tipo particular de rede.

\section{A posição de Barreiras e a ascensão de Luís Eduardo Magalhães}

Com a inserção de capital agrícola nas áreas de cerrado a partir das décadas de 1970 e 1980, a rede urbana do Oeste Baiano foi se reestruturando em torno das necessidades da agricultura moderna. Nesse contexto, destaca-se a inserção de atividades voltadas para o campo nos centros tradicionais, sobretudo Barreiras, e nos novos aglomerados criados pela própria agricultura moderna, tais como Roda Velha, no município de São Desidério, Rosário, no município de Correntina, Novo Paraná (topônimo com referência à origem de migrantes paranaenses) e Mimoso do Oeste, no então território municipal de Barreiras, que, inclusive, leva à "mobilização da força de trabalho" (SANTOS FILHO, 1989, p. 146; SANTOS; CHAVES, 2014).

Os investimentos iniciais da agricultura moderna, ressaltando o fluxo de capital privado oriundo de cooperativas lideradas por agricultores sulistas, destinaram-se para Barreiras, demandando desse núcleo suporte funcional para atender ao ramo agrícola e às atividades urbanas (SANTOS FILHO, 1989). Dentre as principais cooperativas, destacaram-se a Cooperativa Agropecuária do Oeste da Bahia e Cooperativa Agrícola dos Cerrados do Brasil Central Ltda. (SANTOS; CHAVES, 2014).

Entre os recentes aglomerados oriundos da agricultura moderna, Mimoso do Oeste, originado em 1974, com a instalação de uma pensão para caminhoneiros e um posto de combustíveis (BRANDÃO, 2012), destacou-se pela célere ascensão, contabilizando 2.385 habitantes, em 1991 (MOTTA, 2017). Segundo o IBGE (2016), Mimoso do Oeste foi reconhecido oficialmente na condição de distrito de Barreiras no ano de 1997, passando a se denominar Luís Eduardo Magalhães em 1998. Emancipou-se em 2000, sendo essa força emancipatória resultante de interesses políticos de elites agroindustriais 
(BRANDÃO, 2012).

No decorrer desse processo de instauração do capital agrícola nos cerrados baiano, foi verificado que os elementos da rede urbana do Oeste Baiano, tais como a gênese, posição geográfica, tamanho dos núcleos, funções urbanas dos respectivos centros, bem como as interações espaciais derivadas dessas funções, e, por fim, o padrão espacial da própria rede urbana - elementos esses destacados por Corrêa (2004) - foram modificados.

A respeito da gênese, nota-se que os núcleos tradicionais, assim como Barreiras, possuíam vínculo com a atividade portuária, derivando uma rede de padrão simples dendrítico, desde o final do século XIX (SANTOS FILHO, 1989), enquanto que os novos aglomerados da agricultura moderna emergiram às margens das principais rodovias instauradas na região (SANTOS, 2016).

Verificou-se que a posição geográfica de Barreiras foi melhorada à medida que a malha rodoviária se ampliava, formando um conjunto de rodovias federais entroncado em seu núcleo urbano, tais como a BR-020, BR-135 e BR-242. Além de apresentar uma importância derivada desse entroncamento, Barreiras se configurou como centro de gestão do território no Oeste Baiano por concentrar órgãos estatais e mais ampla diversidade de atividades industriais, comerciais e de serviços. Por essa razão, foi considerado, pelo IBGE (2008), como o centro de maior importância do Oeste Baiano, qualificado como capital regional $\mathrm{C}$, apresentando máxima hierarquia regional e mantendo maior área de influência dentre os centros do Oeste Baiano. Por outro lado, Luís Eduardo Magalhães apenas cumpria funções de centro local, segundo o mesmo estudo ${ }^{1}$.

A respeito do tamanho dos centros de Barreiras e Luís Eduardo Magalhães, segundo o IBGE (2010), constatou-se maior concentração populacional urbana em Barreiras, cujo núcleo, em 2010, era composto por 123.741 habitantes, o equivalente a $30 \%$ da população urbana regional, se considerar a população urbana regional total de 411.962 habitantes dos respectivos 31 núcleos componentes dessa rede urbana (Tabela 1); posteriormente, em Luís Eduardo Magalhães, com 54.881 habitantes, o equivalente a $13 \%$ da população urbana regional.

Tabela 1 - Oeste Baiano: tamanho dos centros em população urbana em 2010

\begin{tabular}{lcc|lcc}
\hline Centro & População & $\%$ & Centro & População & $\%$ \\
\hline Barreiras & 123.741 & 30 & Angical & 6.531 & 2 \\
Luís Eduardo Magalhães & 54.881 & 13 & Serra do Ramalho & 6.274 & 2 \\
Santa Maria da Vitória & 23.816 & 6 & Coribe & 6.141 & 1 \\
Barra & 22.446 & 5 & Serra Dourada & 6.002 & 1 \\
Santa Rita de Cássia & 14.907 & 4 & Wanderley & 5.878 & 1 \\
Formosa do Rio Preto & 13.647 & 3 & Mansidão & 4.782 & 1 \\
Santana & 13.483 & 3 & Tabocas do Brejo Velho & 3.932 & 1 \\
Correntina & 12.604 & 3 & Baianópolis & 3.482 & 1 \\
Carinhanha & 12.585 & 3 & Feira da Mata & 3.243 & 1 \\
Riachão das Neves & 10.744 & 3 & Canápolis & 3.225 & 1 \\
São Félix do Coribe & 10.587 & 3 & Cristópolis & 3.133 & 1 \\
São Desidério & 8.633 & 2 & Jaborandi & 3.040 & 1 \\
Cocos & 8.572 & 2 & Brejolândia & 1.984 & 0 \\
Buritirama & 7.905 & 2 & Muquém de São Francisco & 1.283 & 0 \\
Sítio do Mato & 6.866 & 2 & Catolândia & 967 & 0 \\
Cotegipe & 6.648 & 2 & Total & 411.962 & 100 \\
\hline Fonte: & \multicolumn{5}{c}{}
\end{tabular}

Fonte: IBGE, 2010.

\footnotetext{
10 estudo denominado Regiões de Influência das Cidades, de 2007, apoiou-se na concepção utilizada no estudo denominado Divisão do Brasil em Regiões Funcionais Urbanas, de 1972, ao classificar e delimitar áreas de atuação dos centros brasileiros, no entanto, privilegiando a gestão do território, localidades de órgãos estatais e sedes de empresas cujas decisões incidiram em outros espaços, e complementando com atividades de comércio e serviços, atividade financeira, ensino superior, saúde, internet, redes de televisão e transporte aéreo. Posteriormente, foram investigadas as ligações entre as localidades centrais, a intensidade dos relacionamentos e a dimensão das regiões de influência. Em ordem decrescente, a classificação ficou estabelecida em: grande metrópole nacional (São Paulo), metrópole nacional, metrópole, capital regional A, capital regional B, capital regional C, centro sub-regional A, centro sub-regional B, centro de zona A, centro de zona B e centro local (IBGE, 2008).
} 
Ainda na primeira década do século XXI, Barreiras e Luís Eduardo Magalhães figuravam como os principais centros da rede urbana do Oeste Baiano por concentrarem grande parte dos estabelecimentos comerciais e industriais. Enquanto Barreiras reunia um total de 1.960 estabelecimentos comerciais frente aos 1.468 estabelecimentos de Luís Eduardo Magalhães, Luís Eduardo Magalhães reunia 453 estabelecimentos industriais frente aos 419 estabelecimentos de Barreiras (IBGE, 2016).

A respeito das funções urbanas, destacam-se agentes intrínsecos da agricultura moderna, tais como cooperativas agrícolas, agroindústrias, tradings e distribuidores de maquinários agrícolas. Dentre as principais cooperativas agrícolas, podem ser verificadas a Cooperativa Agropecuária do Oeste da Bahia (COOPROESTE), com unidades em Luís Eduardo Magalhães e nos aglomerados de Roda Velha e Novo Paraná, atuantes no processo produtivo de semente de soja; e a Cooperativa Agrícola dos Cerrados do Brasil Central Ltda. (COACERAL), com unidade em Barreiras, voltada para o comércio atacadista de alimentos para animais (SANTOS, 2016).

Dentre as principais agroindústrias em Barreiras, tem-se a Cargill, com sua indústria de esmagamento de soja, na produção de farelo, com destino para a alimentação animal, e no refino de óleo de soja, bem como no fornecimento desse óleo para a produção de biodiesel; em Luís Eduardo Magalhães, tem-se a Galvani, indústria de fertilizantes, e a Bunge, com a indústria de processamento de soja e de refino do óleo da soja, além de unidades de armazenamento nos distritos de Roda Velha e Rosário (SANTOS, 2016).

Em referências às tradings, verificam-se unidades de armazenamento da Archer-Daniels Midland (ADM), da Noble, da Louis Dreyfus Company e da Multigrain, em Luís Eduardo Magalhães (SANTOS; CHAVES, 2014; SANTOS, 2016); e, ainda, da SLC Agrícola, com unidades de produção, entre algodão, girassol, mamona, milho, soja, sorgo e trigo, nos municípios de Barreiras, Correntina, Formosa do Rio Preto, Jaborandi e São Desidério (SANTOS, 2016).

Em referência aos principais distribuidores de maquinários agrícolas (concessionárias de tratores e demais equipamentos agrícolas), em Luís Eduardo Magalhães são identificados representantes da Agrale, da Case ih Agriculture (presente também em Roda Velha, no município de São Desidério, e Rosário, no município de Correntina), da John Deere (presente também em Barreiras, Formosa do Rio Preto, Roda Velha e Rosário), da Massey Ferguson (presente também em Rosário) e da Valtra (também presente em Rosário) (SANTOS, 2016).

No setor terciário nota-se também a concentração do comércio e da prestação de serviços modernos em Barreiras e Luís Eduardo Magalhães. Enquanto esses dois centros reúnem unidades das redes de varejo Lojas Americanas, Magazine Luiza, Novo Mundo, Pague Menos e Real Calçados, bem como as concessionárias de automóveis Chevrolet, Fiat, Mitsubishi Motors e Toyota, Barreiras se diferencia, incluindo as redes de varejo Atacadão, Casas Bahia, Havan e Le Biscuit, e concessionárias de automóveis Ford, Honda, Hyundai, Land Rover, Mercedes Benz, Nissan, Renault e Volkswagen (SANTOS, 2016).

Em geral, Barreiras e Luís Eduardo Magalhães acolheram e desenvolveram atividades demandadas pela agricultura moderna, especialmente Luís Eduardo Magalhães, por concentrar e desempenhar funções inerentes ao agronegócio, transformando-se em lugar de gestão local e regional dessa atividade, por concentrar a produção agrícola e agroindustrial da região (ELIAS, 2011). Enquanto que Barreiras, por sua vez, manteve-se como principal centro regional por concentrar maior população e quantidade e diversidade de estabelecimentos comerciais e de serviços, além de apresentar uma área de influência expressiva, ultrapassando os limites regionais do Oeste Baiano (SANTOS; CHAVES, 2014), sustentada, basicamente, por uma posição geográfica ainda favorável.

É importante mencionar que as interações espaciais, segundo Corrêa (1997, p. 279), tratam-se de "um amplo e complexo conjunto de deslocamentos de pessoas, mercadorias, capital e informação sobre o espaço geográfico", de tal forma que esse elemento em específico se torna merecedor de uma 
discussão à parte do proposto neste escrito.

Diante da interconexão desse conjunto de elementos constituintes da rede urbana regional, notase, no Oeste Baiano, no início do século XXI, um padrão espacial de rede urbana de média complexidade em formação, porém com múltiplos circuitos, tendo em vista a própria complexidade da organização socioespacial da região. Destaca-se que, no âmbito dessa complexidade, forças políticas ganharam protagonismos nos últimos anos: seja pela tentativa de emancipação regional para a criação da unidade federativa do estado do São Francisco, a partir da década de 1990, liderada, principalmente, por sulistas, tendo o movimento fortalecido pelo processo de modernização da agricultura (MARTINS, 2001); seja pela projeção de instauração da ferrovia de integração OesteLeste (BRASIL, 2009), cujo traçado atende aos municípios de Barreiras e Luís Eduardo Magalhães; seja pela recente criação do Plano de Desenvolvimento Agropecuário do Matopiba (alusão às siglas dos estados do Maranhão, Tocantins, Piauí e Bahia), referente a um conjunto de políticas públicas voltadas para o desenvolvimento econômico dessa região, onde o Oeste Baiano está inserido em sua grande parte (BRASIL, 2015). Essas forças, embora dependentes de uma conjectura políticoeconômica nacional favorável às suas implementações, são fatores cruciais para possíveis mudanças na própria rede urbana regional em termos de estrutura e conteúdo.

A respeito do padrão espacial de múltiplos circuitos, Corrêa (1989, p. 77) aponta ser um padrão “[...] resultante da ação de vários processos, cada um implicando localizações específicas, datadas de uma lógica que, se não é inexorável, é simultaneamente própria a cada atividade e ao momento de sua implantação, e geral no âmbito do capitalismo". De modo que os centros se diferenciam "segundo a posição na hierarquia de lugares centrais e segundo as especializações produtivas que apresentam" (CORRÊA, 2012, p. 207), nesse padrão recente, tem-se Barreiras desempenhando papéis de centro macrorregional, com uma área de influência que ultrapassa os limites regionais do Oeste Baiano, e se destacando pela posição geográfica privilegiada concernente ao entroncamento das principais rodovias federais da região, convergindo para si um conjunto de estradas favorável para os contatos com os centros de seu entorno, bem como mantendo contatos diretos com os centros superiores, como Salvador, Brasília e Belo Horizonte, como verificado por meio da atividade aeroportuária (SANTOS, 2016).

Ademais, Barreiras segue como fornecedor de um conjunto de bens e serviços considerável, com atividades seletivas ligadas aos circuitos horizontais e verticais, como serviços de saúde especializados, ensino público técnico e superior, grandes redes de varejo, concessionárias de automóveis e entre outros, atendendo a demanda local, regional e no âmbito externo regional.

Enquanto as horizontalidades são, sobretudo, a fábrica da produção propriamente dita e o locus de uma cooperação mais limitada, as verticalidades dão, sobretudo, conta dos outros momentos da produção (circulação, distribuição, consumo), sendo o veículo de uma cooperação mais ampla, tanto econômica e politicamente, como geograficamente. (SANTOS, 2014, p. 284)

Em uma posição secundária, tem-se, nessa rede urbana regional, Luís Eduardo Magalhães, que vem se estruturando em torno de atividades especializadas para a agricultura moderna, sobretudo agroindústrias e serviços especializados para o campo, como distribuidores de maquinários, atendendo a demanda local e regional com serviços do terciário ligados intrinsicamente às verticalidades do circuito da produção agrícola. Esse centro é também possuidor de uma posição geográfica favorável no que se refere ao entroncamento de rodovias federais, BR-020 e BR-242, e ponto de referência para os recentes aglomerados da agricultura moderna, como Novo Paraná, Roda Velha e Rosário. Por sua vez, Luís Eduardo Magalhães cresce vertiginosamente, em curto espaçotempo, em termos de população e serviços, exercendo, semelhante e tendencialmente, papel de centro regional (SANTOS, 2016). 


\section{Considerações Finais}

Na recombinação dos principais elementos da rede urbana do Oeste Baiano, resultantes de processos sociais, políticos e econômicos ocorridos a partir da década de 1970, dentre os quais se destacam as melhorias da posição geográfica dos centros, com a substituição da circulação fluvial pela rodoviária, e aqueles diretamente resultantes da inserção da agricultura moderna na região, que atraiu população e um conjunto de atividades que alteraram, sobretudo, as funções urbanas dos principais centros a partir das décadas 1970 e 1980, foi verificada uma reestruturação do padrão espacial desse segmento de rede.

Esses processos resultaram em uma urbanização que vem se manifestando em termos quantitativos e qualitativos nos centros tradicionais e nos novos aglomerados, inclusive aqueles em estágios elementares. Ressalva-se Luís Eduardo Magalhães que se destaca pela célere ascensão, atribuída a uma especialização funcional apoiada na agricultura moderna. Tal ascensão faz frente a Barreiras, principal centro desse segmento de rede urbana no oeste da Bahia desde a década de 1970. Barreiras conserva seu papel regional apoiado no setor terciário. Porém, ambos direcionam suas funcionalidades urbanas no sentido de ampliar as centralidades das atividades, seja para o atendimento direto da população, seja para o atendimento das demandas especializadas na agricultura moderna, e consequentemente ampliar a polarização regional, nessas primeiras décadas do século XXI.

Portanto, sobrepõe-se à antiga forma espacial simples de rede urbana, anterior à década de 1980, um padrão espacial de média complexidade e com múltiplos circuitos ainda em estágio constitutivo. Nesse, observa-se a ascensão de Luís Eduardo Magalhães e as estratégias de manutenção da posição em Barreiras, resultante da concentração social, política e econômica, sobretudo nos investimentos de capital e infraestruturas nesses dois centros.

\section{Referências}

BESSA, Kelly Cristine Fernandes de Oliveira. Periodização e diferenciação espacial no segmento de rede urbana no Tocantins. In: SANTOS, Roberto de Souza; LIRA, Elizeu Ribeiro; CALAÇA, Manoel; CHAVEIRO, Eguimar Felício (orgs.). Território e diversidade territorial no cerrado: projetos regionais, cidades e conflitos socioespaciais (vol. II). Goiânia: Kelps, 2015. p. 173-222.

Proposições para a análise da diferenciação espacial nos estudos sobre rede urbana: as noções de convergência e divergência. GEOUSP, São Paulo, n. 28, p. 34-58, 2010.

BRANDÃO, Paulo Roberto Baqueiro. Barreiras e Luís Eduardo Magalhães: uma aglomeração urbana embrionária no Oeste Baiano? In: DIAS, Patrícia Chame; SANTOS, Janio. (Orgs.). Cidades médias e pequenas: contradições, mudanças e permanências nos espaços urbanos. Série Estudos e Pesquisas. 1. ed. Salvador: Superintendência de Estudos Econômicos e Sociais da Bahia, 2012, v. 94, p. 183-195.

BRASIL. Decreto no. 8.447 de 06 de maio de 2015. Dispõe sobre o Plano de Desenvolvimento Agropecuário do Matopiba e a criação de seu comitê gestor. Diário Oficial da União, Brasília, DF, 06 mai. 2015. Disponível em: <http://www.planalto.gov.br/ccivil_03/_Ato20152018/2015/Decreto/D8447.htm>. Acesso em 02 ago. 2016.

Ministério dos Transportes. Relatório de Impacto Ambiental (RIMA): Ferrovia de Integração Oeste-Leste (EF-334) entre Figueirópolis (TO) e Ilhéus (BA), 2009. Disponível em: $<$ http://licenciamento.ibama.gov.br/Ferrovias/EF-

334_Ferrovia\%20de\%20Integra\%C3\%A7\%C3\%A3o\%200este\%20Leste\%20-\%20FIOL_205208/RIMA.pdf >. Acesso em: 15 mai. 2017.

CORRÊA, Roberto Lobato. Redes geográficas: reflexões sobre um tema persistente. Revista Cidades, Presidente Prudente, v. 9, n. 16, p. 199-218, jul./dez. 2012. 
A rede urbana: reflexões, hipóteses e questionamentos sobre um tema negligenciado. Revista Cidades, Presidente Prudente, v.1, n.1, p.65-78, jan./jun. 2004.

CORRÊA, Roberto Lobato. Interações espaciais. In. CASTRO, Iná Elias de; GOMES, Paulo Cesar da Costa; CORRÊA, Roberto Lobato (orgs.). Explorações geográficas: percursos no fim do Século. Rio de Janeiro: Bertrand Brasil, 1997, p. 279-318.

A rede urbana. Série Princípios. São Paulo: Ática, 1989.

DINIZ, José Alexandre Felizola. A área Centro-Ocidental do Nordeste. Recife, SUDENE, 1982.

ELIAS, Denise. Agronegócio e novas regionalizações no Brasil. Revista Brasileira de Estudos Urbanos e Regionais, Recife, v. 13, n. 2, nov. 2011, p. 153-167.

INSTITUTO BRASILEIRO DE GEOGRAFIA E ESTATÍSTICA (IBGE). Cidades, 2016. Disponível em: <http://www.cidades.ibge.gov.br>. Acesso em: 01 nov. 2016.

. Censos demográficos - 2010 e 2000.

Regiões de Influência das Cidades 2007. Rio de Janeiro: IBGE, 2008.

MARTINS, Herbert Toledo. A fragmentação do território brasileiro: a criação de novos estados no Brasil. Caderno CRH, Salvador, n. 35, p. 263-288, jul./dez. 2001.

MOTTA, Margarida Cunha de Miranda. Povoados da Bahia, 2017. Disponível em: <http://www.sei.ba.gov.br/index.php?option=com_content\&view=category\&id=1442\&Itemid=101>. Acesso em: 15 mai. 2017.

SANTOS, Camila Dutra dos; CHAVES, Maria Lucenir Jerônimo. Difusão do agronegócio e urbanização no Nordeste: as regiões produtivas do agronegócio da soja no oeste da Bahia e da fruticultura no baixo curso do rio Açu/Jaguaribe (CE/RN). Geografia Ensino \& Pesquisa, Santa Maria, v. 18, n. 2, P. 3956, mai./ago. 2014.

SANTOS, Iann Dellano da Silva. A organização socioespacial da rede urbana do Oeste Baiano. 2016. 103f. Dissertação (Mestrado em Geografia) - Universidade Federal do Tocantins, Porto Nacional, 2016.

SANTOS, Milton. A natureza do espaço: técnica e tempo, razão e emoção. São Paulo: EDUSP, 2014.

SANTOS, Milton; SILVEIRA, Maria Laura. O Brasil: território e sociedade no início do século XXI. 17a ed. Rio de Janeiro: Record, 2013.

SANTOS FILHO, Milton. 0 processo de urbanização no Oeste baiano. Série de estudos urbanos. Recife: SUDENE-DPE-URB, 1989. 